\title{
System Approach to Bulk Material Flow Control on an Electromagnetic Vibratory Feeder
}

\author{
Petar Mišljen ${ }^{1)}$ \\ Željko Despotovićc ${ }^{2)}$ \\ Milan Matijević ${ }^{1)}$
}

\begin{abstract}
This paper studies the closed-loop control of an electromagnetic vibratory feeder (EVF). Two different linear design procedures have been employed: a conventional proportional-integral-derivative (PID) controller, and a model predictive control (MPC) controller. All derived results have been validated by computer simulation of a nonlinear mathematical model of the system. The results have proved that both controllers achieve a good tracking of the desired output in a selected operating point. In comparison to the PID controller, the MPC controller is more sensitive to disturbances in the form of changes in the mass of material being transported
\end{abstract}

Key words: model predictive control, electromagnetic actuator, vibratory feeder, flow control.

\section{Nomenclature}

$Q_{1}[\mathrm{~kg} / \mathrm{sec}] \quad$ - The flow of material from the inlet hopper, adjusted using a latch;

$Q_{2}[\mathrm{~kg} / \mathrm{sec}]=-$ The flow of material through the trough;

$=Q[\mathrm{~kg} / \mathrm{sec}]$

$v(t)[\mathrm{m} / \mathrm{sec}] \quad$ - Speed of the bulk material via the trough;

$a[m]$

- Trough width;

$i_{c}(t)[\mathrm{m} / \mathrm{sec}]$

- EVA coil current;

$I_{c}[m A]$

$H[m]$

$h(t)[m]$

$f_{c}[N]$

- The average value of the coil current;

- Maximum height level of the material in the trough;

- Height level of the material in the trough directly below the shutter;

- The horizontal component of the resulting excitation forces that acts on the trough;
$A[\%]$

$\rho\left[\mathrm{kg} / \mathrm{m}^{3}\right]$

$T$ [sec]

$S\left[m^{2}\right]$

- Excitation power parameter;

- Density of the bulk material;

- Period of mechanical oscillation;

- Cross-sectional area of the latch.

\section{Introduction}

$\mathrm{T}_{\mathrm{H}}^{\mathrm{H}}$ HE problem of vibration is present in many areas and it is the subject of various studies. Electromagnetic vibratory feeders (EVFs) have a wide range of application in the process industry for bulk materials (conveying, dosing, screening, etc.). An electromagnetic vibratory actuator (EVA) is used as an electromechanical driving device. The transport of bulk materials is done through the vibratory trough. The vertical component of vibratory acceleration acts on bulk materials and make micro-throw of material particles $[1,2]$.
Changes in the conveying rate of the material can be made by changing the vibration excitation frequency and dual vibration amplitude of the vibrating trough [3,4]. EVA is an electromagnetic generator of a mechanical force. This force is proportional to the square of the EVA current. It is possible to control the frequency and duration of an electromagnetic force by changing the parameters of the excitation current. Under these conditions, the whole conveying system with an EVF can be treated as a controllable mechanical oscillator [5-8]. The use of elastic elements is justified because they allow for the creation of conveyors without the use of mechanical elements such as gears, cams belts, bearings, eccentrics or motors, which makes electromagnetic vibratory conveyors and EVFs the most cost-effective equipment $[7,8]$. The springs are under the greatest stress in the upper and lower parts [9]. If the EVF operates in a resonant mode, the desired material flow will be achieved with a minimum energy consumption. The amplitude of oscillation is limited to the construction of the EVF and can be controlled by proper amplitude control. Since the resonant frequency depends on the stiffness of the spring and the quantity of material to be transported, it is necessary to find and monitor the right resonant frequency to achieve energy efficiency. This can be achieved with an appropriate amplitude-frequency control. In this way, the EVF achieves the minimum power consumption $[5,6]$ and improves the input power factor of the regulated EVF operation [10]. A power factor correction (PFC) converter is included in the power converter of the EVF and it is in fact the pre-regulator that stabilizes the mains $\mathrm{AC}$ voltage $230 \mathrm{~V}$ to $400 \mathrm{VDC}$. The cited references $[5,7,8,11]$ discuss the structure of the controller for the EVA, the motion of a linear vibratory feeder and control algorithms, but they do not treat the problem of bulk material flow. The main contribution of this paper is to propose a control strategy for the bulk material flow on an electromagnetic vibratory linear

\footnotetext{
1) Department of Applied Automatic Control, Faculty of Engineering, University of Kragujevac, Kragujevac, SERBIA

2) Department of Robotics and Mechatronics, Mihajlo Pupin Institute, University of Belgrade, 11000 Belgrade, SERBIA

Correspondence to: e-mail: petarmisljen@gmail.com
} 
feeder. The accepted model of the EVF was implemented in Simulink/Matlab and experimentally verified.

\section{Mathematical model of vibratory feeder loaded with material to be transported}

\section{Mathematical EVF model}

A detailed description of a nonlinear model of an EVF is shown in the cited literature [12] and this model has been used in this paper. The experimental setup, which is shown in Fig.1, includes the following instruments: (1) a multimeter; (2) an oscilloscope; (3) a DC power supply for sensors; (4) a control unit with an insulated-gate bipolar transistor (IGBT) converter; (5) digital scales; (6) an actuator and (7) an inlet hopper with shutter.

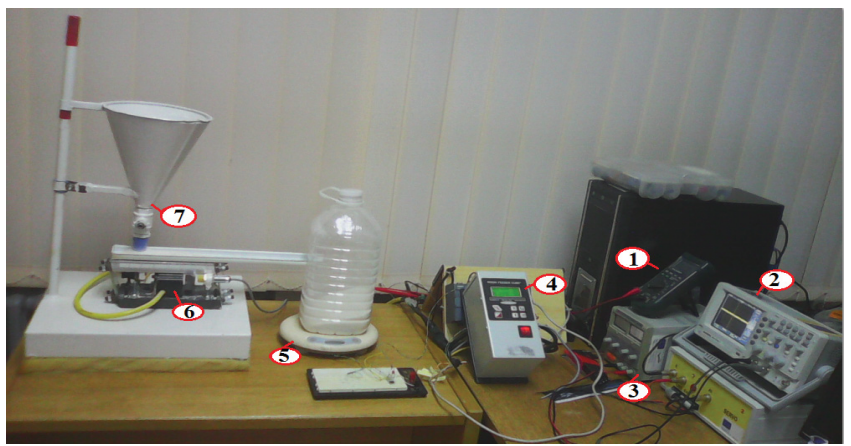

Figure 1. The experimental setup

The entire system is powered by a main power of $220 \mathrm{~V} / 50 \mathrm{~Hz}$. The IGBT converter generates an excitation current of EVA on the principle of pulse-width modulation (PWM). The EVA transforms electromagnetic energy into kinetic energy of the vibrating trough. The flow of material from the inlet hopper to the vibratory trough takes place gravimetrically and is controlled using a shutter. The control unit uses signals from the following sensors: an acceleration sensor mounted on the base plate of the vibrating trough; a displacement sensor of the trough; a force sensor of the weighed material and a current sensor. All signals are monitored on an oscilloscope. The acceleration sensor $(\mathrm{P} / \mathrm{N}$ 123-215) was attached to the vibratory trough. The control unit uses the signal from this sensor to monitor the amplitude and frequency of oscillation. The displacement sensor (TURCK NI10-M18-LiU) was mechanically fastened to the base. The signal at the output of this sensor is proportional to the distance of the trough relative to the base. The mean value of the coil current is measured by a digital multimeter (MZ8268). The current sensor (AS712T) is used for monitoring current with the oscilloscope (GDS-1052-U). The IGBT converter is controlled by the control unit, based on the reference value of the excitation frequency and excitation power parameter $(\mathrm{A}[\%])$, the measured value of the flow of material through the trough $\left(Q_{2}[\mathrm{~kg} / \mathrm{sec}]\right)$ and the EVA coil current $\left(i_{c}(t)[A]\right)$. The variable $p[\mathrm{~m}]$ represents a displacement of the moving armature core in a horizontal plane. The EVA coil current is a periodic signal and can be expanded in terms of sinusoidal components. A Fourier series representation of the EVA coil current is:

$$
i_{c}(t)=\frac{3 A_{m}}{8}+\sum_{k=1}^{\infty} \frac{8 A_{m}}{3 \pi^{2} k^{2}}\left(1-\cos \frac{k 3 \pi}{4}\right) \cos k \omega t
$$

On the basis of equation (1) and experimental measurements, the dependence of the amplitude of the coil current on the parameter $A$ is determined as:

$$
A_{m}=8 A+\frac{8}{3} 50[\mathrm{~mA}]
$$

In this work, the envelope detector was simulated as a diode peak detector. The velocity of the material flowing through the vibrating trough is calculated based on the value of the parameter $p[\mathrm{~m}]$. The material flow rate is calculated based on the speed of the material through the trough and the known dimensions of the trough. The relative movement of the bulk material in relation to the vibrating trough and modeling of the height level of the bulk material in a vibrating trough have been decrypted in the literature [12].

\section{Validation of the vibratory feeder simulation model}

Fig. 2 shows the dependence of the bulk material flow and average value of the EVA current on the EVA current frequency $(f[\mathrm{~Hz}])$, obtained by simulation. The mathematical model refers to an EVF with an excitation frequency equal to the mechanical resonant frequency $\left(f_{m r}[\mathrm{~Hz}]\right)$. For this reason, the flow characteristic is only valid for excitation frequencies that are near the resonant frequency.

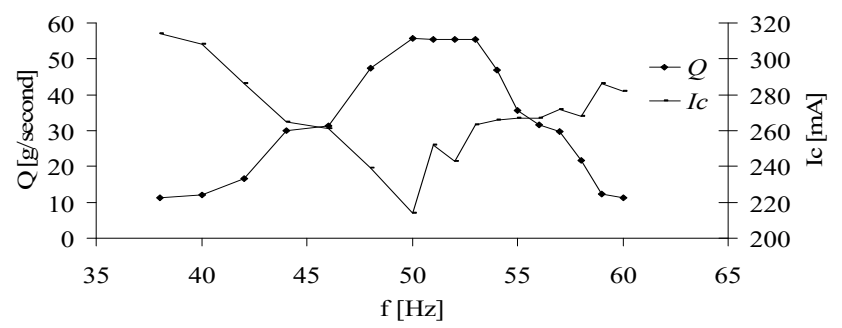

Figure 2. The flow characteristic depending on frequency and average value of the EVA current $\left(I_{c}\right), f_{m r}=51.5 \mathrm{~Hz}, \mathrm{~A}=50 \%$, simulation

Fig. 3 shows experimental results of measuring the flow of bulk material and the average value of the EVA current depending on the frequency of the EVA current pulses.

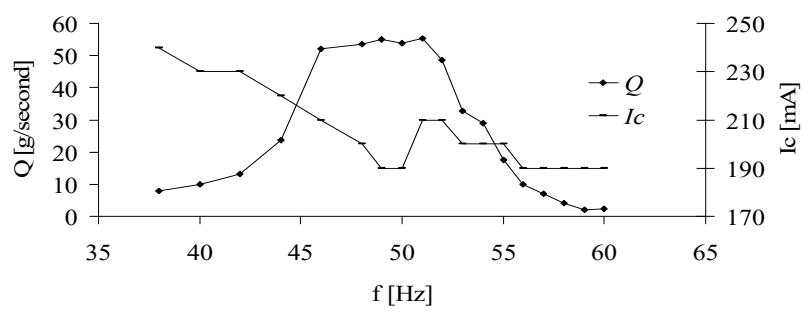

Figure 3. The flow characteristic depending on frequency and average value of the EVA current $\left(I_{c}\right), f_{m r}=51.5 \mathrm{~Hz}$, experimental results

The transmission characteristics are shown in Fig.4 for the experiment $\left(p_{\exp }[\mathrm{mm}]\right)$ and for the simulation $\left(p_{\text {sim }}[\mathrm{mm}]\right)$, respectively.

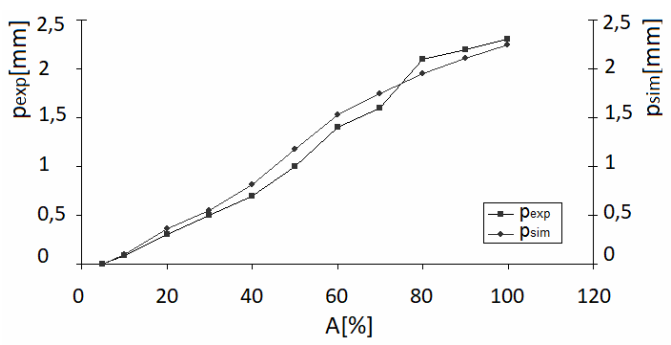

Figure 4. The transmission characteristics of the EVF for displacement $P[\mathrm{~mm}]$ 
Comparing Fig.2 to Fig.3, and considering Fig.4, it can be concluded that the adopted model of the EVF can be deemed a valid one. The ratio of parameter $A[\%]$ and the amplitude of oscillations $P[\mathrm{~mm}]$ are explained in detail in the literature [12].

\section{Model simplification}

For the application of the MPC controller in the adopted model, it is necessary to select an EVF operating point in order to simplify the model and to present a simplified model in state space. The dependence of the bulk material flow rate with respect to the value of the parameter $A[\%]$ is shown in Fig.5. This figure was obtained using a simulation $\left(f_{m r}=51.5 \mathrm{~Hz}\right)$.

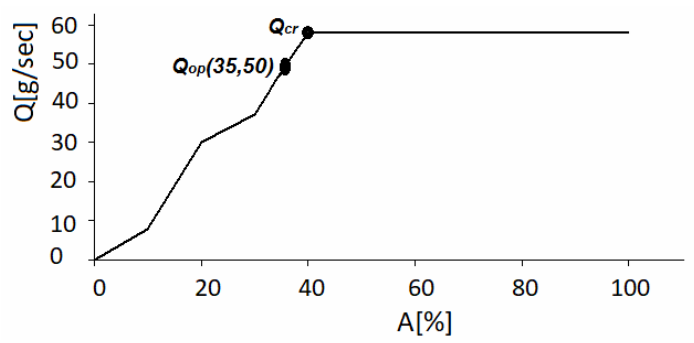

Figure 5. The transmission characteristics of the EVF for the material flow $\mathrm{Q}[\mathrm{g} / \mathrm{sec}]$

In this investigation, an operating point $Q_{o p}(35,50)$ has been selected, as shown in Fig.5. The step response of the EVF was simulated for 12 seconds. Parametric identification of the nonlinear model of the EVF was performed using the function 'ident' in Simulink/Matlab, based on the calculated values of parameters $p[\mathrm{~m}]$ and $Q[\mathrm{~kg} / \mathrm{sec}]$. Equations (3) and (4) describe the EVF model obtained by linearization of the nonlinear model of the EVF in the adopted operating point. These equations are obtained by the parametric identification based on the response of the nonlinear system to the Heaviside step function excitation.

$$
\begin{gathered}
G_{1}(s)=\frac{P(s)}{A(s)}=\frac{2.002 \cdot 10^{-5}}{1+0.077663 s} e^{-0.037 s} \\
G_{2}(s)=\frac{Q(s)}{P(s)}=\frac{2.22}{s^{2}+26.75 s+310.8} e^{-0.022}
\end{gathered}
$$

\section{Control strategies}

This paper discusses two strategies of the flow control of bulk materials. The first is the application of a PID controller, and the second is the use of a MPC controller. The design of the PID controller was based on the step response of the nonlinear model of the EVF. The design of the MPC controller was based on the linearized model of the EVF. The validity of the MPC controller was checked using the nonlinear model of the EVF. The EVF step response with an open loop, which was obtained by simulation in Simulink/Matlab, is shown in Fig.6 $(A=35 \%)$.

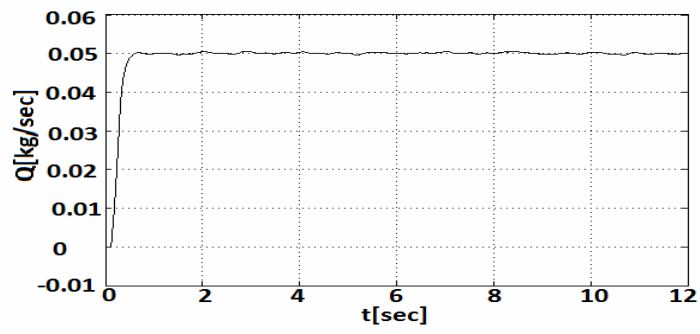

Figure 6. EVF step response with an open loop
The gain of the system in a stationary state $\left(K_{p}\right)$ and the time constant $\left(\tau_{P}\right)$ are determined from Fig.6. If $\tau_{C}$ is the time constant of the system with a closed loop, then the $\tau_{\text {RATIO }}$ parameter is defined as:

$$
\tau_{R A T I O}=\frac{\tau_{C}}{\tau_{P}}
$$

The equation of the PID controller is in the form:

$$
G=K_{C}\left(1+\frac{1}{T_{I}} \int e(t) d t+T_{D} \frac{d e(t)}{d t}\right)
$$

The PID controller parameters are determined according to the following:

$$
K_{C}=\frac{1}{K_{P} \tau_{\text {RATIO }}}, T_{I}=\tau_{P}, T_{D}=0
$$

A closed-loop EVF was created using a PID controller block for two characteristic values of the $\tau_{R A T I O}$ parameter. The obtained simulation results are shown in Figures 7 and 8.

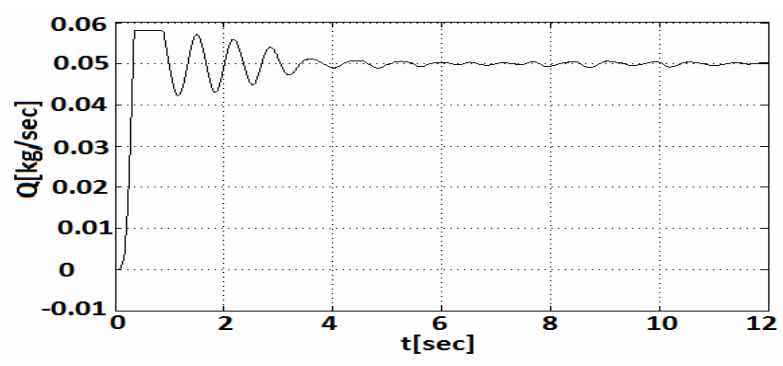

Figure 7. EVF output controlled by PI controller, $\tau_{\text {RATIO }}=2$

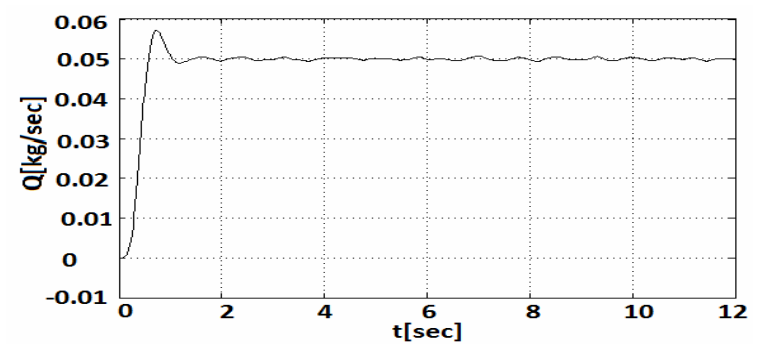

Figure 8. EVF output controlled by PI controller, $\tau_{\text {RATIO }}=4$

The value of the control signal is limited to $39 \%$ and the reference value of the output is set to $50 \mathrm{~g} / \mathrm{sec}$. In Figures we can see that it is possible to obtain a satisfactory step response of the system by a proper selection of the PID controller parameters. An increase in the value of the parameter $t$ results in greater damping of its own oscillations. The MPC controller simulations were carried out in Simulink/Matlab using the "mpctool" function. Controller design description, identification and modelling studies are presented in the literature [13]. The transfer function in the state space is determined from equations (3) and (4). Input is a parameter $\mathrm{A}[\%]$, and outputs are displacement (p) and flow rate (Q). In this paper, we examined two MPC controllers that differ in the number of controlled outputs. In the first case, only the value of the bulk material flow ( $Q[\mathrm{~kg} / \mathrm{sec}]$ ) was observed. In the second case, two outputs, the bulk material flow ( $Q[\mathrm{~kg} / \mathrm{sec}]$ and displacement $(p[\mathrm{~m}])$, were observed. Constraints used in the simulations are the next: $0<A[\%] \leq 39,0<p[\mathrm{~mm}] \leq 2.5,0<Q[\mathrm{~g} / \mathrm{sec}] \leq 58$. 


\section{Results}

In order to verify the effectiveness of the proposed control algorithms, simulation experiments were performed on the EVF nonlinear model. Fig.9 shows the reference signal that was used in simulation without the influence of external disturbances on the monitored systems.

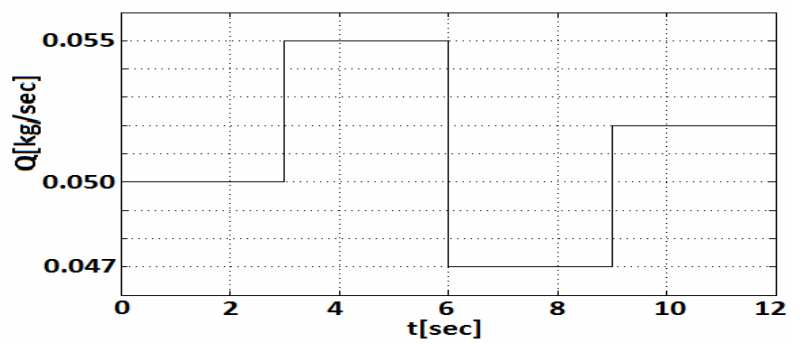

Figure 9. Reference signal for simulation experiment.

For PID control, PI block $\left(\tau_{\text {RATIO }}=4\right)$ has been used. The resulting system response is shown in Figure 10. The EVF responses with the abovementioned MPC controllers for the reference signal shown in Fig.9 are shown in Figures 11 and 12. The results show that it is sufficient to observe only one output state in case of MPC controller. In this case, it is the bulk material flow rate $\mathrm{Q}$. This fact simplifies the control algorithm, which is of particular importance to the practical implementation of MPCs.

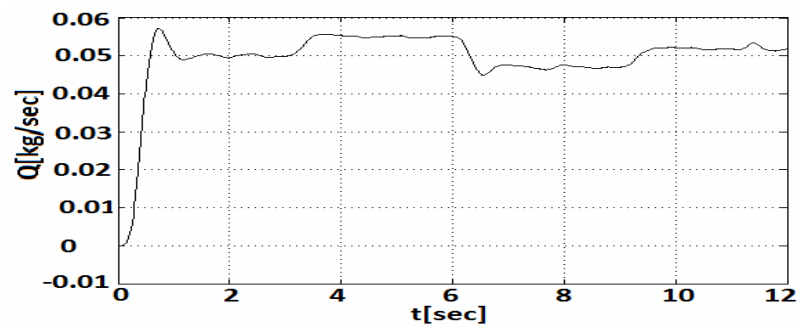

Figure 10. The EVF output controlled by PI controller, $\tau_{\text {RATIO }}=4$.

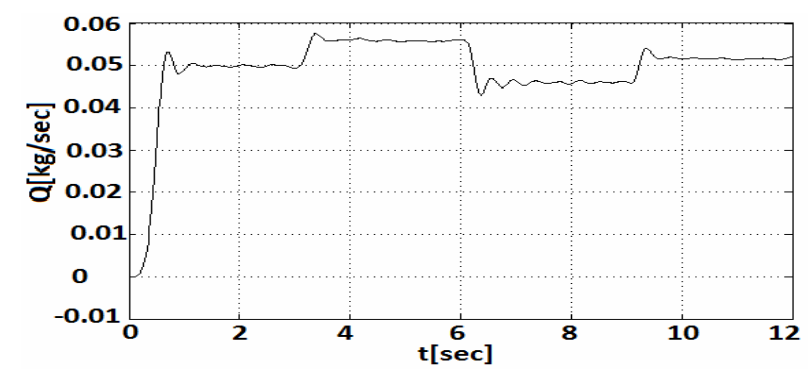

Figure 11. The EVF output controlled by MPC, $Q[\mathrm{~kg} / \mathrm{sec}]$ was observed.

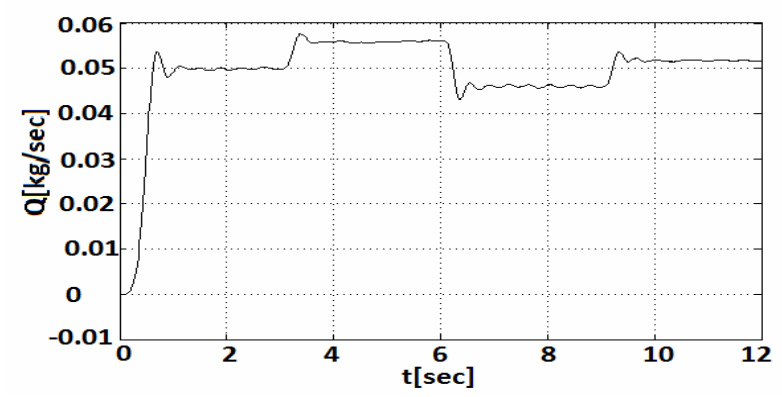

Figure 12. The EVF output controlled by MPC, $Q[\mathrm{~kg} / \mathrm{sec}]$ and $p[\mathrm{~m}]$ were observed.

During the investigation it was found that a decrease in the control interval of MPCs, up to ten times, did not significantly improve the response of the system with a closed loop. The results in Figures 11 and 12 show that the EVF is a robust system. Without external disturbances, the proposed control algorithms do not improve the step response of the EVF. In order to test the proposed control algorithms, the system was exposed to disturbance in form of changes in the material mass being transported. The material mass was increased by $7.5 \%$ in two seconds. The changes in material mass $(\Delta m)$ are shown in Fig.13. The response of the system without a closed loop is shown in Fig.14. The responses of PID and MPC controllers to this disturbance are shown in Figures 15 and 16, respectively. Fig. 15 shows that the proposed methodology for the selection of parameters for the PID controller depends on the nature of the EVF. The controller keeps the set value of the flow of material, with acceptable deviations in steady state. Fig.16 shows that, compared to the PID controller, the MPC controller is significantly more sensitive to the observed disturbance. Given that the system was made to operate in a resonant mode, this behaviour of the MPC controller is expected. Changing the mass of the material causes a change in the EVF mechanical resonance. In this case, previously adopted model of the system is no longer adequate for the applied MPC controller.

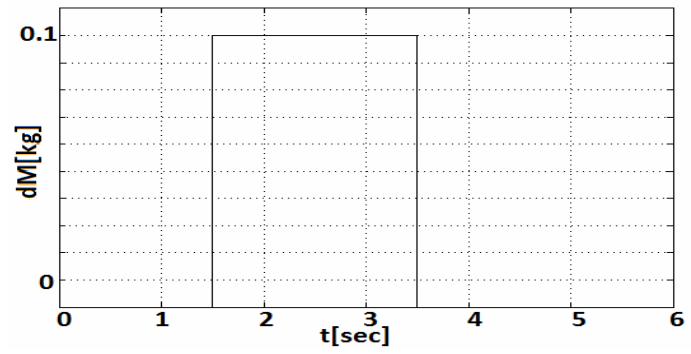

Figure 13. The changes of the material mass

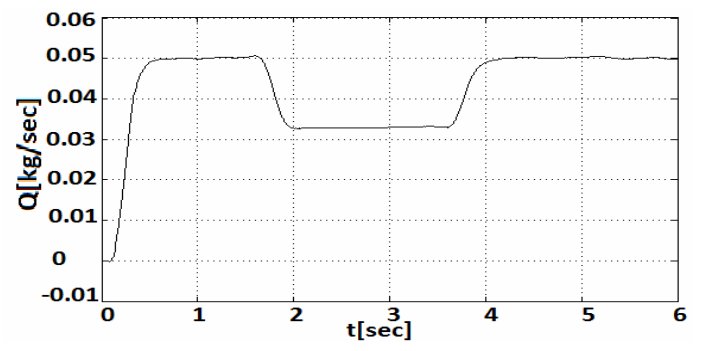

Figure 14. The response of the EVF without a closed loop.

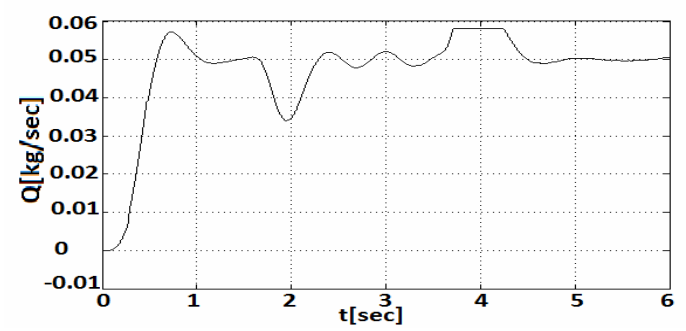

Figure 15. The response of the EVF with PID controller.

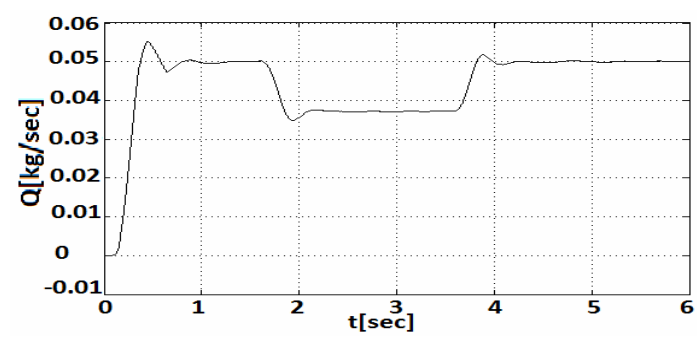

Figure 16. The response of the EVF with MPC controller. 


\section{Discussion}

This paper presents the results of a design procedure for the control of bulk material flow rate on an EVF. A comprehensive investigation has been carried out on the mathematical modeling and computer simulation of dynamic behaviour of a whole nonlinear system, based on real laboratory experimental data. Two strategies of bulk material flow control are discussed. The first is the application of a PID controller and the second is the application of a MPC controller. The tune rule for the PID controller is a first order closed-loop response. The PID controller shows a very good tracking performance, with acceptable tracking error within the considered operating range.

MPC controller simulations were carried out in Simulink/Matlab using the "mpctool" function. A simplified mathematical model was used as a basis to design the MPC controller. The MPC controller shows a good tracking performance in the selected operating point. In case of a change of the setpoint, an error in the stationary state appears as result of the EVF nonlinearity. To achieve the same results as with the PID controller, it is necessary to use more MPC controllers, one for each of the expected mechanical resonances. The design and implementation of the PID controller is simpler solution, and therefore less expensive from the standpoint of time and the competence of human resources employed to put the system into operation and then maintain it. It has been shown that the PID control, in comparison with the MPC, provides better results in case of disturbances in form of changes in the mass of the material being transported. The MPC controller is applicable when the system operates in a resonant mode. If the system comes out of resonant mode, the response of the MPC controller worsens. This sensitivity of MPC controllers to disturbances in form of changes in the mass of material to be transported reduces the scope of application of these controllers in the field of vibrating transport.

\section{References}

[1] HAN,L., TSO,S.K.: Mechatronic design of a flexible vibratory feeding system, Proceedings of the Institution of Mechanical Engineers, Part B: Journal of Engineering Manufacture 2003; 217(6): pp.837-842.

[2] SLOOT,E.M., KRUYT,N.P.: Theoretical and experimental study of the transport of granular materials by inclined vibratory conveyors, Powder Technology 1996; 87(3): pp.203-210.

[3] PARAMESWARAN,M.A., GANAPAHY,S.: Vibratory ConveyingAnalysis and Design: A Review, Mechanism and Machine Theory 1979; 14(2): pp.89-97.

[4] MC GLINCHEY,D.: Vibratory Conveying Under Extreme Conditions: An Experimental Study, Advanced in Dry Processing 2002, Powder/Bulk Solids 2001; 1: pp. 63-67.

[5] DOI,T., YOSHIDA,K., TAMAI,Y., KONO,K., NAITO,K., ONO,T.: Modelling and feedback control for vibratory feeder of electromagnetic type, Journal of Robotics and Mechatronics 1999; 11(5): pp. 563-572.

[6] DESPOTOVIC,Z., STOJILJKOVIC,Z.: Power converter control circuits for two-mass vibratory conveying system with electromagnetic drive: Simulations and experimental results, IEEE Trans. Ind. Electron. 2007; 54(1): pp. 453-466.

[7] RIBIĆ,A.I., DESPOTOVIC,Z.: High-Performance Feedback Control of Electromagnetic Vibratory Feeder, IEEE Transaction on Industrial Electronics 2010; 57(9): pp.3087-3094.

[8] DESPOTOVIĆ,Ž.V., RIBIĆ,A.I., SINIK,V.: Power Current Control of a Resonant Vibratory Conveyor Having Electromagnetic Drive, Journal of Power Electronics 2012; 12(4): pp.678-689.

[9] VUJOVIĆ,M., DESPOTOVIĆ,Ž.: Dynamic Stress Distribution in Composite Leaf Springs for Electromagnetic Vibratory Feeder, In: 3rd International Conference \& Workshop Mechatronics in Practice and Education (MECHEDU); 14-16 May 2015; Subotica, Serbia.

[10] DESPOTOVIC Z.V., LECIC M., JOVIC M., DJURIC A.: Vibration control of resonant vibratory feeder with electromagnetic excitation, Journal FME Transactions 2014; 42(4): pp. 281-289.

[11] DESPOTOVIC,Z., URUKALO,DJ., LECIC,M., COSIC,A.: Mathematical modelling of resonant linear vibratory conveyor with electromagnetic excitation: simulations and experimental results, Applied Mathematical Modeling 2017; 41(1): pp.1-24.

[12] MISLJEN,P., DESPOTOVIC,Z., MATIJEVIC,M.: Modeling and Control of Bulk Material Flow on the Electromagnetic Vibratory Feeder, Automatika 2016; 57(4): pp.936-937.

[13] DILA,G.: Model predictive controller design of hydrocracker reactors, Turk J Elec Eng \& Comp Sci 2011; 19(5): pp.817-825.

\title{
Sistemski pristup kontroli protoka rasutog materijala primenom elektromagnetnog vibracionog dozatora
}

\begin{abstract}
U ovom radu je proučavano upravljanje elektromagnetnim vibracionim dozatorom u sistemu sa zatvorenom povratnom spregom. Razmatrana su dva slučaja linearnih upravljačkih struktura: klasičan proporcionalno-integralno-diferencijalni (PID) uskladnik i prediktivni MPC (Model Predictive Control) uskladnik. Svi dobijeni rezultati su verifikovani kompjuterskom simulacijom nelinearenog matematičkog modela sistema. Rezultati su pokazali da oba uskladnika postižu dobro praćenje željenog izlaza u izabranoj radnoj tački. U poređenju sa PID uskladnikom, MPC uskladnik je osetljiviji na smetnje u obliku promena mase materijala koji se transportuje.
\end{abstract}

Ključne reči: prediktivno upravljanje na osnovu modela, elektromagnetni pokretač, vibracioni dozator, upravljanje protokom. 